International Journal of Medical Anesthesiology 2021; 4(2): 242-244

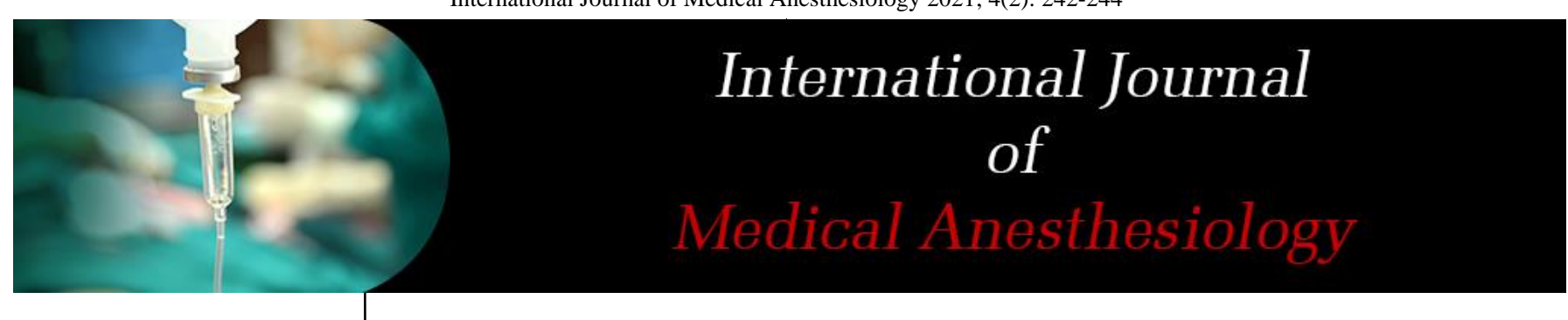

E-ISSN: 2664-3774

P-ISSN: 2664-3766

www.anesthesiologypaper.com

IJMA 2021; 4(2): 242-244

Received: 13-02-2021

Accepted: 15-03-2021

Dr. Ranjitha YS

Assistant Professor,

Department of Anaesthesia,

Seth GSMC and KEM

Hospital, Maharashtra, India

Dr. Vaishakh Ramesh

Junior Resident, Department

of Anaesthesia, Seth GSMC

and KEM Hospital,

Maharashtra, India

Dr. Govinda Innani

Junior Resident, Department

of Anaesthesia, Seth GSMC

and KEM Hospital,

Maharashtra, India

Dr. Anita N Shetty

Professor, Department of

Anaesthesia, Seth GSMC and

KEM Hospital, Maharashtra,

India

Corresponding Author:

Dr. Ranjitha YS

Assistant Professor,

Department of Anaesthesia,

Seth GSMC and KEM

Hospital, Maharashtra, India

\section{Airway management in a large posterior cervical neurofibroma: A case report}

\author{
Dr. Ranjitha YS, Dr. Vaishakh Ramesh, Dr. Govinda Innani and \\ Dr. Anita N Shetty
}

DOI: https://doi.org/10.33545/26643766.2021.v4.i2d.263

\begin{abstract}
Neurofibromas are benign nerve sheath tumours which may present as stand-alone variants or may be present in association with neurofibromatosis type-1 (NF-1) in which myriads of disfiguring and bulging masses emanate from nerves, connective tissue and skin.

We hereby report successful airway management of a 27 year old female with Von recklinghausen disease (NF-1) who presented with multiple neurofibromas along with a large posterior cervical neurofibroma for excision of posterior cervical neurofibroma.
\end{abstract}

Keywords: von recklinghausen disease, posterior cervical neurofibroma, airway management

\section{Introduction}

Neurofibromatosis type 1 is an autosomal dominant genetic disorder. NF1 gene located on chromosome $17 \mathrm{q} 11.2$ is responsible for transcription and translation of protein neurofibromin which is involved in inhibition of cell proliferation ${ }^{[1]}$. Mutation of this gene leads to abnormal cell growth forming neurectodermal and mesodermal tumours [2]. Neurofibromas in head and neck region pose daunting airway challenge to anaesthesiologist. Herein, we report the successful use of awake videolaryngoscopic technique for intubation in a patient with large posterior cervical neurofibroma.

\section{Case report}

We present a case of 27 year old female with progressively enlarging mass over a course of few years in the posterior aspect of neck with associated tingling and weakness in right upper limb that was posted for excision of the mass. There was no history of dyspnoea or dysphagia which ruled out laryngeal and pharyngeal neurofibromas. On examination, there was a large mass extending from occipital region till lower part of posterior neck region. Neck extension was grossly restricted due to the mass. Airway parameters measurement revealed that the neck circumference was $42 \mathrm{~cm}$ which was increased due the mass, thyromental distance was $6.5 \mathrm{~cm}$, hyomental distance was $4.5 \mathrm{~cm}$, inter-incisor distance was $5.5 \mathrm{~cm}$ and mallampati grade was 1 . Patient could lie supine with head turned towards one side due to the mass. MRI of whole spine revealed diffuse homogeneously enhancing thickening of bilateral cervical nerve roots extending from $\mathrm{C} 1$ to $\mathrm{C} 7$ with significant focal cord compression at $\mathrm{C} 4-\mathrm{C} 5$ level along with multiple neurofibromas in posterior cervical region, lower back and gluteal region.

Our plan A was airway anaesthesia and awake videolaryngocopic technique of intubation with C-Mac with back up plans of fibre optic bronchoscope guided intubation, laryngeal mask airway guided intubation and retrograde intubation as plans $\mathrm{B}, \mathrm{C}$ and $\mathrm{D}$ respectively in case of failed intubation with plan A. Adequate psychological preparation was ensured with detailed explanation of the technique and reassurance and informed consent was obtained. In the operating room, ASA standard monitors were attached. Intramuscular Injection of glycopyrrolate $4 \mathrm{mcg} / \mathrm{kg}$ was given as antisialogogue. Airway anaesthesia was achieved using lignocaine $2 \%$ gargles, lignocaine $4 \%$ nebulisation, superior laryngeal nerve block, recurrent laryngeal nerve block and lignocaine $10 \%$ oropharyngeal spray. Continuous high flow nasal oxygenation at $12 \mathrm{l} / \mathrm{min}$ was started. Injection fentanyl $1 \mathrm{mcg} / \mathrm{kg}$ was given intravenously and Dexmedetomidine infusion was started at $0.5 \mathrm{mcg} / \mathrm{kg} / \mathrm{hr}$. Patient comfortably lied supine with head turned towards left side. After spraying lignocaine $10 \%$ 
spray, first attempt of laryngoscopy was performed with CMac using blade size 3.

Only epiglottis was visualised but wasn't liftable. Second attempt of laryngoscopy was performed using C-Mac D blade. Epiglottis with arytenoids, posterior part of vocal cords and laryngeal aperture were visible. Laryngoscopy did not reveal any gross laryngeal or pharyngeal neurofibromas. Gum elastic bougie was inserted and intubation was done with $7.0 \mathrm{~mm}$ cuffed endotracheal tube. Nasal oxygenation was continued until cuff inflation and confirmation of endotracheal intubation through capnography. This was followed by injection of propofol $2 \mathrm{mg} / \mathrm{kg}$ and rocuronium $1 \mathrm{mg} / \mathrm{kg}$. The total duration of laryngoscopy and intubation was 3 minutes. Surgery was in prone position and patient was maintained on oxygen and nitrous oxide mixture with sevoflurane. Patient was extubated after surgery uneventfully. Due to adequate psychological preparation and airway anaesthesia, patient had no complaints against anaesthesia induction in postoperative interview.

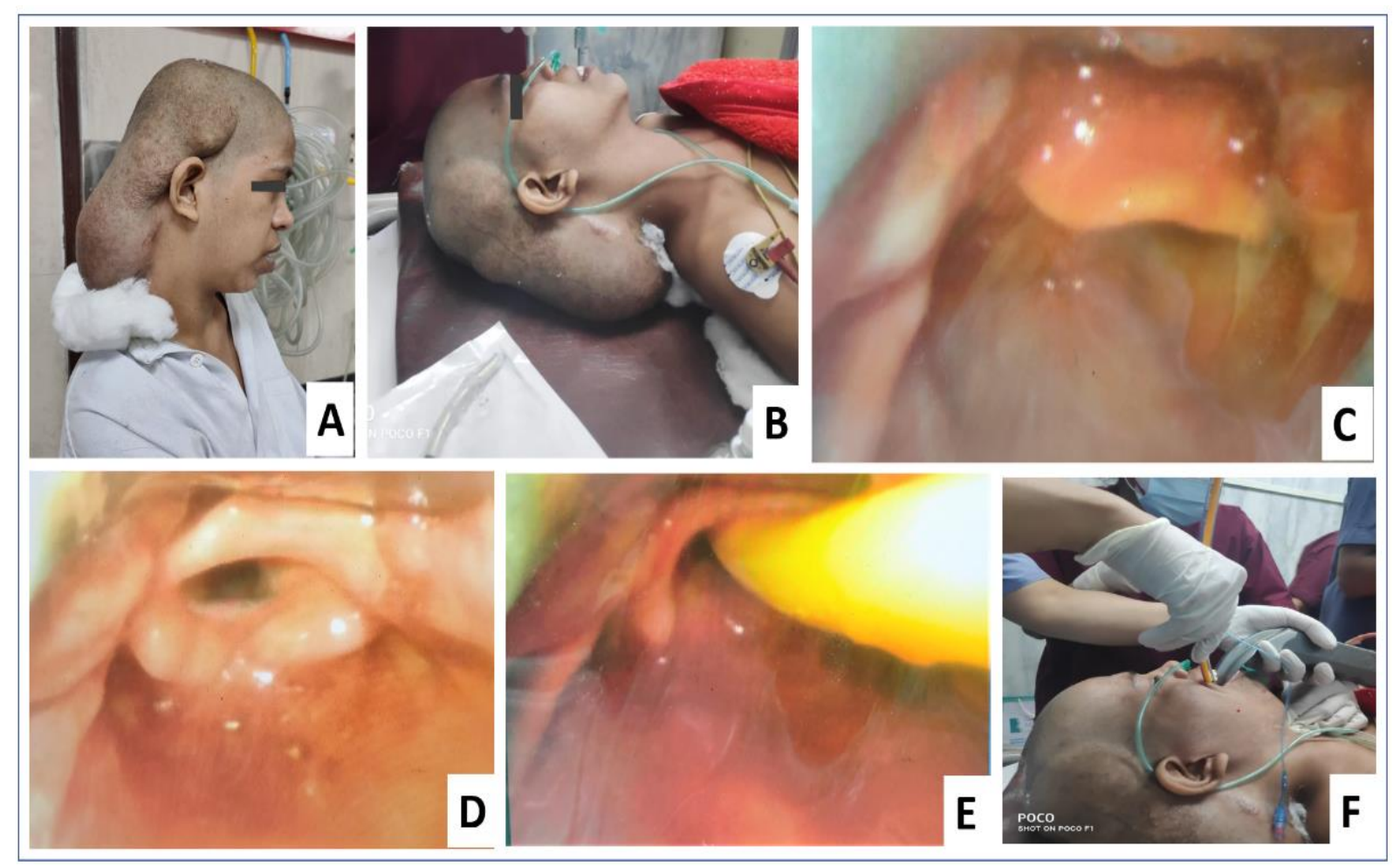

Fig 1: A and B - Showing large posterior cervical neurofibroma. C - View of laryngeal aperture using C Mac blade size 3 which shows epiglottis and arytenoids. D - View of laryngeal aperture using C Mac D-blade which shows epiglottis, arytenoids and vocal cords. E and F Awake Bougie guided Intubation using C Mac D-blade.

\section{Discussion}

Neurofibromatosis (NF) is an autosomal dominant condition belonging to the group of neurocutaneous phakomatoses. Multiple neurofibromas with associated café-au-lait spots, axillary freckles, iris hamartomas, optic nerve glioma and multiple bone dysplasias may be found [3]. Craniomaxillofacial lesions can be divided into massive plexiform, cranioorbital and cervical neurofibromas ${ }^{[4]}$. NF1 poses multitude of challenges to anaesthetists, which include difficult airway due to macroglossia, facial, oropharyngeal, laryngeal and neck masses, as well as difficulty in positioning due to abnormalities of the spinal anatomy, long bone dysplasias and multiple peripheral neurofibromas ${ }^{[5]}$. Other considerations include respiratory compromise due to intrapulmonary fibromas and cardiovascular compromise due to hypertrophic cardiomyopathy, mediastinal tumours and scoliosis leading to right ventricular failure ${ }^{[6]}$. In our case, we chose awake video laryngoscopic technique over awake fibre optic optic technique as they provide a fixed wide view of the glottis that aids easy and quick recognition of airway landmarks [7] as well as familiarity of the technique. Also, awake fibre optic technique has a steep learning curve and in order to reach competence with fibre optic scope-guided intubations
(> $90 \%$ success rate within three minutes), the anaesthetist needs to do at-least 25 intubations ${ }^{[8]}$. We also continued high flow nasal oxygenation till successful endotracheal intubation. Compared to the conventional low-flow nasal cannula oxygen therapy, it has been proven that high-flow nasal cannula (HFNC) oxygen therapy enhances both oxygenation and $\mathrm{CO}_{2}$ clearance ${ }^{[9]}$. Thus in our case, adequate topicalisation of airway, optimal sedation, psychological preparation of patient, simpler and user friendly operational technique of C-Mac video laryngoscope resulted in successful endotracheal intubation in a terrifying airway.

\section{Conclusion}

Awake videolaryngoscopic technique can be used successfully to accomplish endotracheal intubation as an alternative to awake fibre optic technique in case of large posterior cervical neurofibroma.

\section{Declaration of patient consent}

The authors certify that they have obtained all appropriate patient consent forms. In the form, the patient has given her consent for his images and other clinical information to be reported in the journal. The patient understands that name 
and initials will not be published and due efforts will be made to conceal identity, but anonymity cannot be guaranteed.

\section{Financial support and sponsorship}

Nil

\section{Conflicts of interest}

There are no conflicts of interest

\section{References}

1. Lee WY, Shin YS, Lim CS, Chung WS, Kim BM. Spinal anesthesia for emergency cesarean section in a preeclampsia patient diagnosed with type 1 neurofibromatosis. Korean journal of anesthesiology 2013;65(6S):S91.

2. Del Castillo AS, Brito M, Martínez J, Sardi N. Manejo anestésico en cesárea de urgencia en pacientes con enfermedad de Von Recklinghausen: Presentación de dos casos. Revista Mexicana de Anestesiología 2009;32(2):134-7.

3. Guerrero-Domínguez R, López-Herrera-Rodríguez D, Acosta-Martínez J, Jiménez I. Implicaciones anestésicas en la enfermedad de Von Recklinghausen. Revista Colombiana de Anestesiología 2015;43(1):10710.

4. Citak EC, Oguz A, Karadeniz C, Okur A, Memis L, Boyunaga O. Management of plexiform neurofibroma with interferon alpha. Pediatric hematology and oncology 2008;25(7):673-8.

5. Desai A, Carvalho B, Hansen J, Hill J. Ultrasoundguided popliteal nerve block in a patient with malignant degeneration of neurofibromatosis 1. Case Reports in Anesthesiology 2012.

6. Hirsch NP, Murphy A, Radcliffe JJ. Neurofibromatosis: clinical presentations and anaesthetic implications. British journal of anaesthesia 2001;86(4):555-64.

7. Hodzovic I, Bedreag O. Awake videolaryngoscopeguided intubation-well worth adding to your skill-mix. Romanian Journal of Anaesthesia and Intensive Care 2019;26(1):5-7.

8. Heidegger T, Gerig HJ, Ulrich B, Schnider TW. Structure and process quality illustrated by fibreoptic intubation: analysis of 1612 cases. Anaesthesia 2003;58(8):734-9.

9. Nishimura M. High-flow nasal cannula oxygen therapy in adults. Journal of intensive care 2015;3(1):15. 